\title{
Conceptual Framework of Modelling for Malaysian Household Electrical Energy Consumption using Artificial Neural Network based on Techno-Socio Economic Approach
}

\author{
Boni Sena $^{1}$, Sheikh Ahmad Zaki ${ }^{2}$, Fitri Yakub ${ }^{3}$, Nelidya Md Yusoff ${ }^{4}$, Mohammad Kholid Ridwan \\ ${ }^{1,2,3}$ Malaysia-Japan International Institute of Technology, Universiti Teknologi Malaysia, Malaysia \\ ${ }^{4}$ Razak School of Engineering and Advanced Technology, Jalan Sultan Yahya Petra, 54100 Kuala Lumpur, \\ Universiti Teknologi Malaysia, Malaysia \\ ${ }^{5}$ Faculty of Engineering, Gadjah Mada University, Indonesia
}

\section{Article Info \\ Article history: \\ Received Feb 2, 2018 \\ Revised May 21, 2018 \\ Accepted May 28, 2018}

\section{Keyword:}

Artificial neural network Conceptual framework Electrical energy consumption Residential

Techno-socio economic

\begin{abstract}
The residential sector was one of the contributors to the increase in the world energy consumption and $\mathrm{CO}_{2}$ emission due to the increase population, economic development, and improved living standard. Developing a reliable model of electrical energy consumption based on techno-socio economic factors was challenging since many assumptions need to be considered. Over the past decade, bottom-up approaches such as multi-linear regression, artificial neural network (ANN), and conditional demand analysis were used for developing mathematical models to investigate interrelated characteristics among techno-socio economic factors. However, the existing models mostly were focused on countries that had different socio-economic level and cultures from the developing countries of the Association of Southeast Asian Nations. Similar studies in that tropical region were very scarce and only limited for linear modelling under the conditions of techno-socio economic factors. In this study, we proposed ANN for developing a model of electrical energy consumption based on techno-socio economic factors for a tropical region, Malaysia. In order to develop the model, quantitative measurement and qualitative assessment were required. The quantitative measurement was based on the monitoring of total electrical energy consumption with a oneminute interval. In contrast, the qualitative assessment utilized a questionnaire survey to assess household characteristics based on technosocio economic parameters. The objective of this paper was to propose a conceptual framework of the estimation model for household electrical energy consumption with the consideration of techno-socio economic factors using ANN.
\end{abstract}

Copyright $@ 2018$ Institute of Advanced Engineering and Science. All rights reserved.

Corresponding Author:

Sheikh Ahmad Zaki,

Malaysia-Japan International Institute of Technology,

Universiti Teknologi Malaysia,

Jalan Sultan Yahya Petra, 54100 Kuala Lumpur, Malaysia.

Email: sheikh.kl@utm.my

\section{INTRODUCTION}

The advanced emission of carbon dioxide $\left(\mathrm{CO}_{2}\right)$ due to energy consumption is the major cause of environmental impacts such as the ozone layer depletion, global warming and climate change. In fact, the global emissions of $\mathrm{CO}_{2}$ escalated by $28.2 \%$ from 2000 until 2014 [1]. The most significant emissions of $\mathrm{CO}_{2}$ are emanated from fossil fuel combustion for power generation in industrial, building and transport sectors [2]. The building sector consists of commercial and residential contribute to approximately $40 \%$ and $30 \%$ of the global $\mathrm{CO}_{2}$ emissions, respectively [3]. The global average of energy consumption in the residential sector 
accounts for $20 \%$ in developed countries and more than $35 \%$ in developing countries [4]. These trends are expected to increase significantly in the future due to the rapid growths of economic, population and living standard in the world. Under these circumstances, the balance system between energy supply and demand needs to be ensured. Therefore, understanding the characteristics of electrical energy consumption in the residential sector is important for energy measures and on-site power generation.

Most of the previous studies [5]-[8] used top-down and bottom-up approaches for estimating electrical energy consumption in the residential sector. The top-down approach determines the energy consumption of residential sector as a whole like econometric and technological models. The econometric model correlates the energy use with macro-economic variables such as income, fuel price and gross domestic product. The technological model attributes energy consumption for the entire residential sector based on appliance ownership trends and saturation effects of technology development [7]. Zhou and Teng [9] used 11960 samples for urban household survey data from Sichuan Province in China to develop an econometric model for estimating the income and price elasticities of household electricity consumption. They considered the effects of lifestyle variables such as socio-demographic (e.g. family size and education background), residential size, and appliance ownership. Wiesmann et al. [10] developed an econometric model based on data from Cencus in Portuguese mainland for 275 municipalities. They investigated the influence of socio-demographic (e.g. household income and number of occupants), residential characteristic, climatic condition, and geography on electricity energy consumption. Szekeres and Jeswiet [11] developed dynamic models for adoption of heat pump technology to estimate annual energy saving and green house gases emission reduction for the residential sector in Canada.

The bottom-up approach accounts for electrical energy consumption based on occupant behaviour, appliance usage, and indoor and outdoor temperatures [8]. Buratti et al. [12] conducted field measurement on a residential in Perugia to develop building envelopes and thermal model for estimating energy consumption and indoor air temperature in the residential using Transient System Simulation Tool software. Huebner et al. [13] developed four multi-linear regression (MLR) models based on 845 households to investigate contributing factors on annual electrical energy consumption. The model examined socio-demographic factors (e.g. number of occupant, age, employment, and household income), building characteristics, appliance characteristics, and occupant behaviour (e.g environmental awareness, willingness to conduct energy saving behaviour). Matsumoto [14] used survey data from 59374 household of Japan to investigate the contributing factors in the residential electricity consumption and appliance usage based on conditional demand analysis (CDA) models. The models considered appliance ownership (ownership of air conditioning, television, tumble dryers, etc), socio-economic factors (source of income such as labor and non-labor income), and household income (i.e. husband, wife or both).

Stoecklein et al. [15] classified electricity consumption data that collected from 40 residentials in New Zealand for 239 days using Kohonen probabilistic artificial neural network (ANN) based on the source of income (worker or pentioner), load profile shape and absolute power demand. Aydinalp [16] modelled appliance, lighting and space cooling, domestic hot water and space heating using ANN from 8767 households in Canada to estimating the annual average of electricity consumption. These models were developed based on building characteristics (e.g. residential type and tenure type), socio-demographic factors (e.g. number of children and adult, income), appliance characteristics, indoor and outdoor temperatures. Roque [17] developed ANN models from 136 households in multi-unit residential in Toronto, Canada. The model was employed for investigating the impact of socio-demographic factors (gender, age, household income, previous residence, occupancy duration), building orientation and number of hours spent on monthly electrical energy consumption. Szüts and Kromer [18] created an ANN model from 1000 households in Hungary based on socio-demographic factors (family composition, education, and household income) and building characteristics (size and type of residential) to estimate the annual total electricity consumption.

Recently, similar studies in developing countries such as those in a tropical region had been reported [19]-[23]. For example, Wijaya [19] had modelled techno-socio economic factors using MLR from 200 respondents in Bandung and Yogyakarta, Indonesia. The model considered household income, family size, education level, daily activity, floor area, and appliances with respect to the monthly electricity consumption. Azlina et al. [20] assessed factors influencing electricity consumption of residential for 1561 respondents in Terengganu, Malaysia using CDA models. This study investigates the effects of socioeconomic factors (age, gender and occupation background), household characteristics (type of residential, total floor area), attitudinal factors (willingness to conduct energy saving behaviour, values, belief, environmental awareness), and appliance ownership in accordance with electricity energy consumption. Zaki et al. [21] developed model for generating air conditioning operation schedules from 38 residentials in Kuala Lumpur based on period of usage time, start and end times, and frequency of air conditioning events. Ranjbar et al. [22] conducted short-term measurement on electrical energy consumption under hot season weather conditions for ten residents in apartment located at Kuala Lumpur. The study showed that air 
conditioning consumption consumed from $19.4 \%$ to $52.3 \%$ of total electrical energy consumption. Furthermore, Ranjbar et al. [23] investigated energy usage behaviour that showed dissimilar pattern of electrical energy consumption among different residentials. The effect of outdoor temperature was more clearly observed in the night due to hot condition in daytime.

Based on the literature review, most of previous studies for developing energy model based on techno-socio economic approach were conducted in developed countries. Energy model in developed countries might not suitable for developing countries due to different socio-economic level, cultures, and climates condition. Previous studies only focus on estimating average annual or monthly electricity consumption and modeling which are only limited to techno-socio economic factors. There have been no studies that model real time estimation of the total electrical energy consumption in the residential sector based on more comprehensive techno-socio economic factors in the tropical region. The aim of this paper is to propose the bottom-up approach of conceptual framework of ANN that estimates the real time estimation of the total electrical energy consumption based on techno-socio economic factors in Malaysia. All related techno-socio economic factors that affect the total electricity energy consumption are explained in this paper. The proposed conceptual framework integrates the basic model of ANN with techno-socio economic factors as the input of model and short-term real time estimation of total electricity energy consumption as the main output of the model.

\section{ANN MODEL}

ANN models are created based on mimicking the biological nerve networks of the human [24]. It can attribute quantitative real time and qualitative database due in analyzing non-linear and complex causal relationships of input and output with different types of datasets. In addition, the models are not developed based on specific information of the residential system and inner logic of model or so-called black box approach [17]. This approach is suitable to estimate the output of short real time electrical energy consumption based on the inputs of techno-socio economic factors. Figure 1 shows the biological nerve network of human and the basic model of ANN.

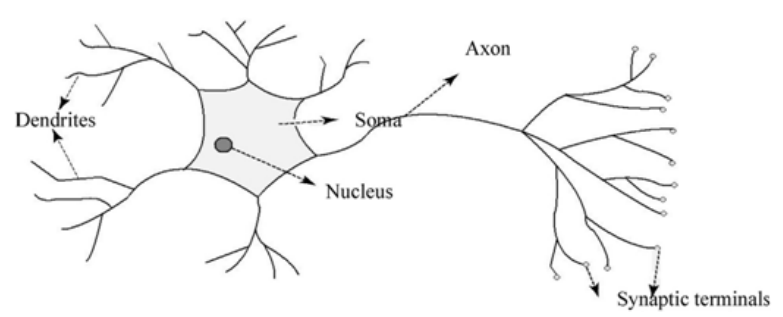

(a)

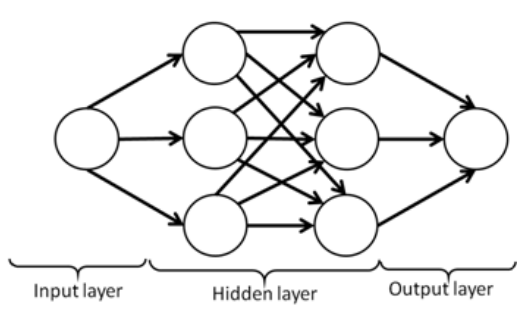

(b)

Figure 1. Concept of ANN (a) biological nerve of human, (b) basic model of ANN [24]

The model development of ANN is divided into some processes which are determining the input and output from datasets, selecting the number of datasets for training, validating and testing, choosing activation function and scaling intervals, and assigning network architecture. The model development of ANN is divided into some processes which are determining the input and output from datasets, selecting the number of datasets for training, validating and testing, choosing activation function and scaling intervals, and assigning network architecture. Input and output are determined based on the objective of model. Determination of the number of datasets for training, validating and testing is required to distinguish datasets based on functions in ANN models. Data training are a group of matched input and output data employed for training the ANN model by modifying the weight function and bias parameter constant. Data validating is utilized to examine the general characteristic of network and to discontinue the process of training after ANN model achieve optimum characteristic. Data testing is employed to verify the ANN models with the input untrained data [17].

Determination of activation function and scaling intervals is applied to select the activation function and scaling intervals. Scaling intervals are needed to keep each data value in the range of the amplitude of the chosen activation function and to avoid the simulated neurons from pushing too far to saturation level [16]. Determination of network architecture can be decided through repeating simulation until the best performances of ANN models are achieved. The basic equation of ANN model can be developed from 
simple ANN model for one neuron. Biswas et al. [25] explained equation of one neuron ANN model as shown in Equation (1) where input (x), weight function (w), bias function $(\theta)$ and output model (y).

$$
\mathrm{y}=\mathrm{f}(\mathrm{xw}+\theta)
$$

$\mathrm{f}(\mathrm{)})$ is an activation function which determines the output of neuron. Some common activation functions are identity function $(\mathrm{y}=\mathrm{x})$, threshold function , and sigmoid function as shown in Equations (2) and (3), respectively [26] where a is the constant threshold.

$$
\begin{aligned}
& f(x)= \begin{cases}1 & \text { if }(x \geq a) \\
0 & \text { if }(x \leq a)\end{cases} \\
& f(x)=\frac{1}{1+e^{x}}
\end{aligned}
$$

Figure 2 shows the example of ANN model for two inputs $\left(\mathrm{x}_{1}\right.$ and $\left.\mathrm{x}_{2}\right)$, one output $(\mathrm{y})$ and one hidden layer. Some equations can be defined based on the example of ANN model as shown in Equations (4), (5), and (6) where $w_{i, j}$ is the weight of input neuron, $\theta_{i}$ is bias function and a,b, c is output function of hidden layer.

$$
\begin{aligned}
& a=f(a)=f\left(x_{1} w_{1,1}+x_{2} w_{1,2}+\theta_{1}\right) \\
& b=f(b)=f\left(x_{1} w_{2,1}+x_{2} w_{2,2}+\theta_{2}\right) \\
& c=f(c)=f\left(x_{1} w_{3,1}+x_{2} w_{3,2}+\theta_{3}\right)
\end{aligned}
$$

The output of ANN model (y) as shown in Equation (7) is defined as total output from hidden layer function $(\mathrm{a}, \mathrm{b}$, and $\mathrm{c})$ and bias function $\left(\theta_{4}\right)$ where $\mathrm{w}_{\mathrm{i}}$ is the weight of output neuron.

$$
y=f(d)=f\left(a w_{1}+b w_{2}+c w_{3}+\theta_{4}\right)
$$

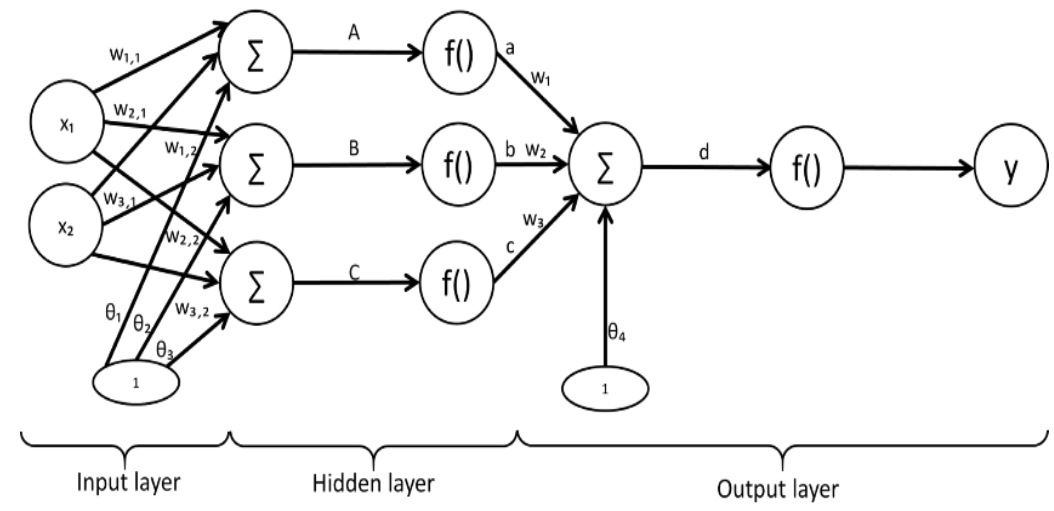

Figure 2. Example of three layers in ANN model [25]

\section{RESEARCH METHODOLOGY}

Research methodologies are divided into three parts which are quantitative measurement, qualitative assessment and model development using ANN. The quantitative measurement is based on monitoring of total electrical energy consumption for 20 residential with a minute interval. The qualitative assessment uses a questionnaire survey to assess determinant factors of the electrical energy consumption based on technosocio economic factors for approximately 400 residents. The results from quantitative measurement and qualitative assessment are used to develop the ANN model. 
The performances of ANN model are attained by detracting the error between the target or actual data and the predicted data. The optimization performance of ANN model can be distinguished into three different types which are the sum of square error (SSE), the mean squared error (MSE) and $\mathrm{R}^{2}$ (Coefficient of correlation). SSE is the average squared difference between set of predicted values and set of real data values. Regression $\mathrm{R}^{2}$ values mean the correlation between set of predicted values and set of real data values. MES is the average squared difference between predicted and real data divided by a number of data points. The process of checking for the ANN model performance is repeated until the model achieve the standard value of SSE, MSE and $\mathrm{R}^{2}$ [25]. Figure 3 shows the research methodology of electrical energy consumption modeling using ANN based on techno-socio economic approach.

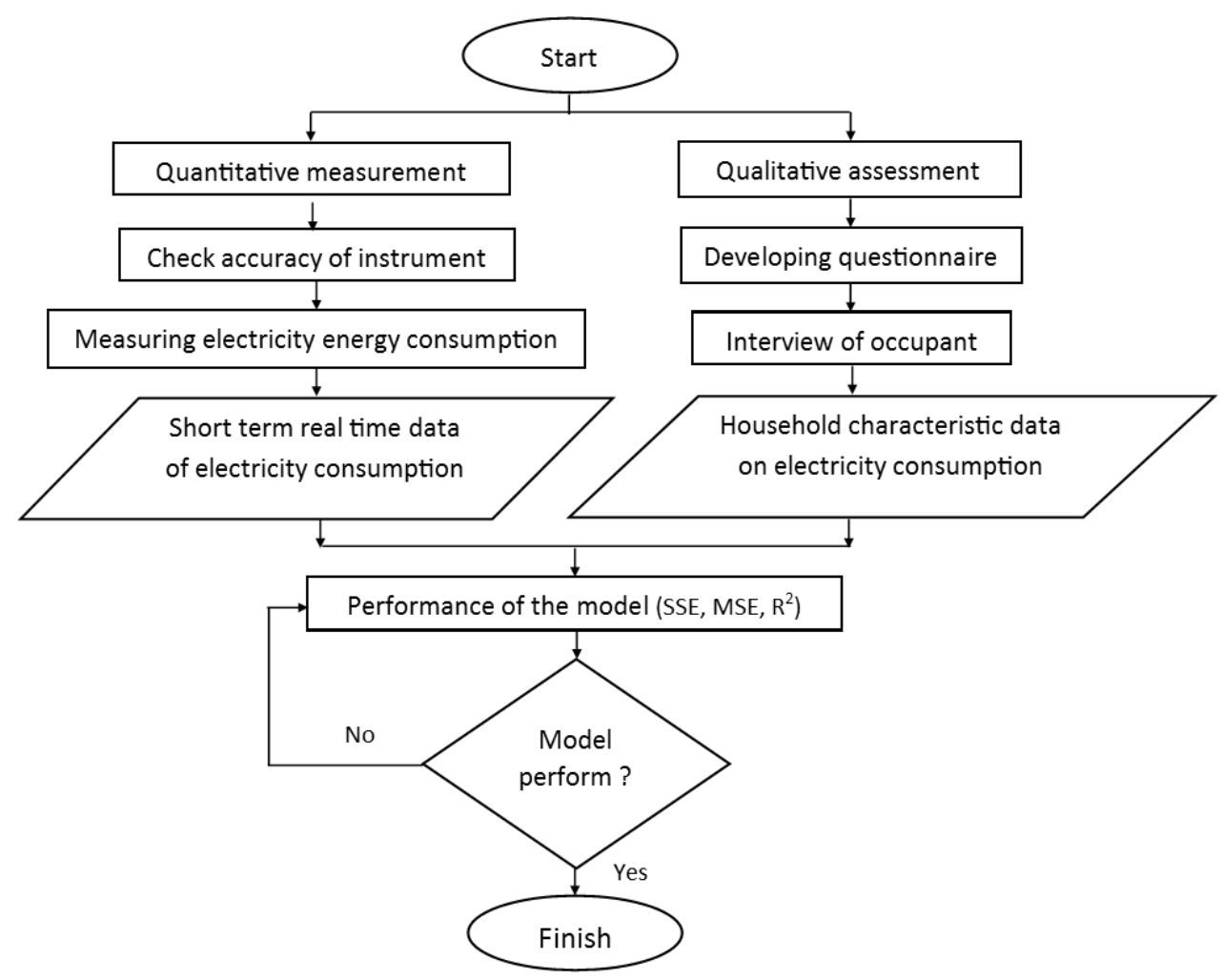

Figure 3. Research methodology of modelling for household electrical energy consumption using ANN based on techno-socio economic approach

\section{TECHNO-SOCIO ECONOMIC FACTORS}

Techno-socio economic factors such as socio-demographic, house characteristic, occupant behaviour in purchasing and using appliance, and appliance characteristic are explained in this section. The reviewed and discussed of the influencing factors on electricity energy consumption in the residential such as socio-economic, residential and appliance characteristics has been reported by Jones et al. [27]. It was found that only a few previous studies which assessed the effect of appliance characteristics such as ownership of appliance, usage behaviour of appliance, and power demand appliance on electrical energy consumption. Occupant behaviour in purchasing and using appliance has significant effects on electricitiy energy consumption as reported by [28], [19], [29], respectively. Occupant behaviour in purchasing energy saving appliance can reduce electrical energy consumption. Furthermore, occupant behaviour in using appliance can increase or reduce electrical energy consumption in residential. The correlation between household income and electrical energy consumption had been explained well by [30]. Occupants who have higher income tend to consume more electrical energy consumption than those who have lower income. Appliance characteristic such as number of appliance ownership and type of appliance can affect electrical energy consumption in residential [13], [31].

\subsection{Socio-demographic}

Socio-demographic factors which consist of a number of occupants, family composition, age, education level, household income and employment status have significant contribution to increasing 
electricity consumption in residential [27]. The number of occupant affects electricity consumption that means the more people living in the residential, the more electrical energy consumption in residential will be [9]. Family compositions with adults and children have higher electricity consumption than family living without children or with other adults. Age of occupant has a direct and indirect effect on electricity energy consumption. The middle age of householder has higher electrical energy consumption due to the presence of children [32]. Meanwhile, older people consume less electricity consumption because they rarely use appliances [33]. The higher education level in a family, the higher also the electricity consumption will be. Higher education is correlated with the wealth of family in residential size and number of ownership appliance [30]. Household income affects electrical energy consumption. The higher household income, the electricity consumption will be higher also [34]. Similar findings from Batih et al. [30] show that higher electricity consumption is found in family with a higher income. This is because the higher income family tends to have more appliances than lower income family. Employment status has indirect effects on electricity energy consumption as reported by Wijaya [19]. A higher education not only leads to a better job with a higher income, it also makes people to spend less time at home. Therefore, the electricity consumption of working people will be less than people who have more time to stay at home.

\subsection{Residential characteristic}

Residential characteristics can be divided into type, the material of wall, the material of roof, residential age, tenure type, total floor area, type of room, orientation, type of glazing, type of shading devices, and glazing ratio. The residential type of semi-detached, terraced and apartment use less weekly electricity compared to detached residential due to the residential size and ownership of high electricity consume appliance [35]. Type of wall, roof and glazing windows can cause significant variance on electrical energy consumption as reported by [13]. Residential age can affect electricity consumption due to the improvement of material building. Brounen et al. [33] found that the thermal building had been improved for new residential. The older residential consumed more electricity than newer ones. Tenure type has effects on electricity consumption in relation with the wealth condition of family. The private owner of the residential consumes more electricity than rented residential [34]. Total floor area has significant effects on electricity consumption in residential [29]. The more total floor area, the more electricity consumption will be used for cooling in summer and heating in winter [9].

\subsection{Occupant behavior in purchasing and using appliance}

Occupant behaviour in purchasing energy-efficient appliances has an effect on electrical energy consumption. Mizobuchi and Takeuchi [28] found that household which purchased energy-efficient air conditioner saved more electricity. Wijaya [19] explained the factors affecting occupant behaviour in purchasing appliances based on product perspectives which are price, brand, energy saving, warranty, user friendliness, technology, safety, model and country of origin. Occupant behavior in using appliance has a significant effect on electrical energy consumption. Huebner et al. [13] found that the use of a heating system can increase electricity consumption. Behaviour in the usage of appliances such as cooling device, cooking device, entertainment and information device can affect electricity consumption in a residential [19]. Bedir et al. [36] examined that the operating time of appliance caused significant variance in electrical energy consumption in residential.

\subsection{Appliance characteristic}

Appliance characteristic had a statistically significant effect on electricity consumption in the residential [13]. The more appliance ownership, the more electricity consumption will be. Bedir et al. [36] explained that the total number of appliances cause variance in electricity consumption. Appliance ownership can affect electricity consumption in residential. Huebner et al. [13] stated that the ownership of the tumble dryer and separate freezer have significant effects on electricity consumption. Wahlström [31] found that the usage of heat pumps could reduce electricity consumption than that which only relies on heating or cooling system. The ownerships of air conditioning, washing machine, personal computer and television have significant effects on electricity consumption in the residential [37]. McLoughlin et al. [32] confirmed that the entertainment appliances (computer, television and game console), washing appliances (tumble dryer and dishwasher) and electric water heater have significant effect on electricity consumption. A household with a refrigerator has higher electricity consumption than that which does not have one refrigerator [9].

\section{CONCEPTUAL FRAMEWORK OF ENERGY EFFICIENCY STRATEGY}

Development of household electrical energy consumption model using ANN based on techno-socio economic approach can be used to propose recommendation of energy efficiency strategy. Figure 4 shows 
conceptual framework of energy efficiency strategy that consists of field survey, electrical energy consumption modelling, characteristic of electrical energy consumption and recommendation of energy efficiency strategy. Energy efficiency strategy can be proposed based on classification of short-term real time of electrical energy consumption and determinant factors of electrical energy consumption. Some examples of energy efficiency strategy that can be proposed are electricity price policy based on peak demand of electrical energy consumption, classification of peak demand of electrical energy consumption based on techno-socio economic factors, development of smart household appliance based on real time pattern of electrical energy consumption, and on-site power generation (photovoltaic, wind energy, and micro hydro). However, the scope of this research only covers for three aspects of the conceptual framework of energy efficiency strategy that consist of field survey, electrical energy consumption modelling and characteristic of electrical energy consumption. Energy efficiency strategy is a potential future research in this field of study.

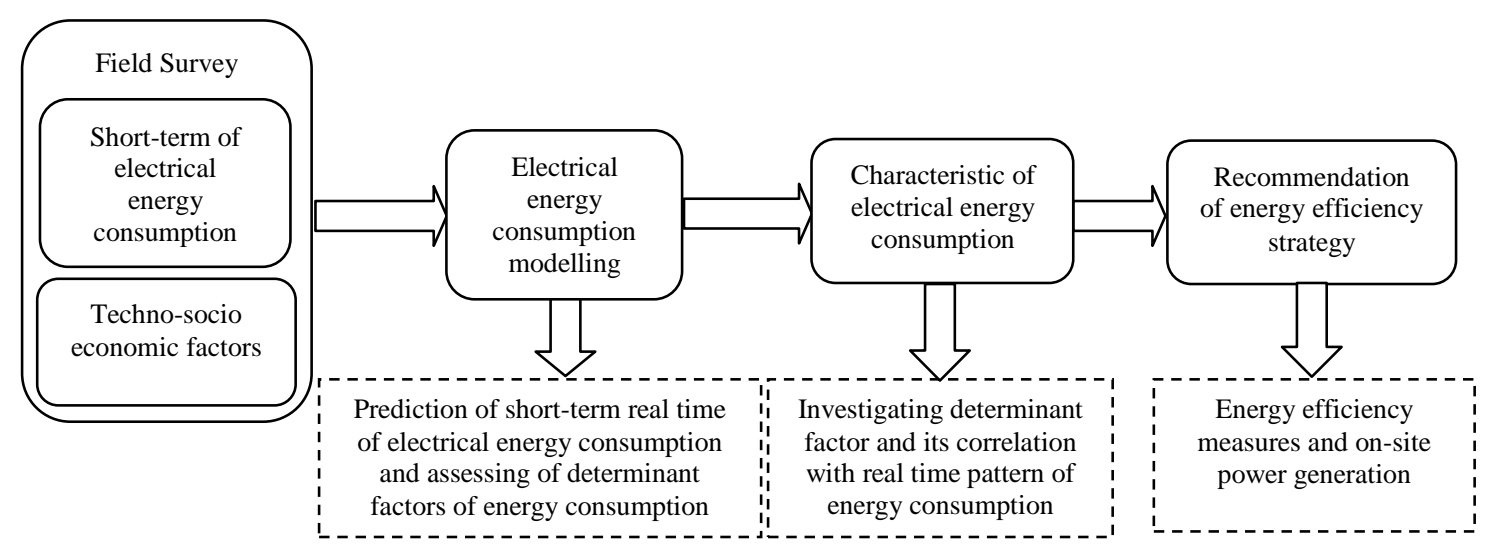

Figure 4. Conceptual framework of energy efficiency strategy

\section{CONCEPTUAL FRAMEWORK OF MODELING FOR MALAYSIAN HOUSEHOLD ELECTRICAL ENERGY CONSUMPTION USING ANN BASED ON TECHNO-SOCIO ECONOMIC APPROACH}

The conceptual framework of the estimation model of electrical energy consumption is developed from three parts which are techno-socio economic parameters i.e. the input model from qualitative assessment, short term total electrical energy consumption as output model from quantitative measurement and ANN model. Figure 5 shows the conceptual framework of ANN model for estimating electricity energy consumption based on techno-socio economic parameters. $X_{i}$ and $X_{j}$ mean the neuron created from the input layer to hidden layer. $\mathrm{W}_{\mathrm{i}, \mathrm{j}}$ mean the weight parameters for each neuron. The bias value $\left(\theta_{\mathrm{i}}\right)$ gives 1 to multiplication between the input layer and weight parameter then the result is proceeded by activation function in the hidden layer. The number of the hidden neuron (n) can be increased or decreased depending on the performance of ANN model. The basic equation for ANN model to estimate short-term of total electrical energy consumption based on techno-socio economic approach are shown in Equation (8) where $\mathrm{w}_{\mathrm{i}}$ is weight parameter of output neuron, $\theta_{\mathrm{k}}$ is bias function of output neuron, and $\mathrm{a}, \mathrm{b}, \mathrm{c}, \mathrm{d}$, e are the output function of hidden layer as shown in Equation (9).

$$
\begin{aligned}
& y=f\left((a+b+c+d+e) \sum_{i=1}^{n} w_{i}+\sum_{k=6}^{n} \theta_{k}\right) \\
& a=b=c=d=e=f\left(\sum_{i=j=1}^{n} x_{i} w_{i j}+\sum_{i=1}^{n} \theta_{i}\right)
\end{aligned}
$$




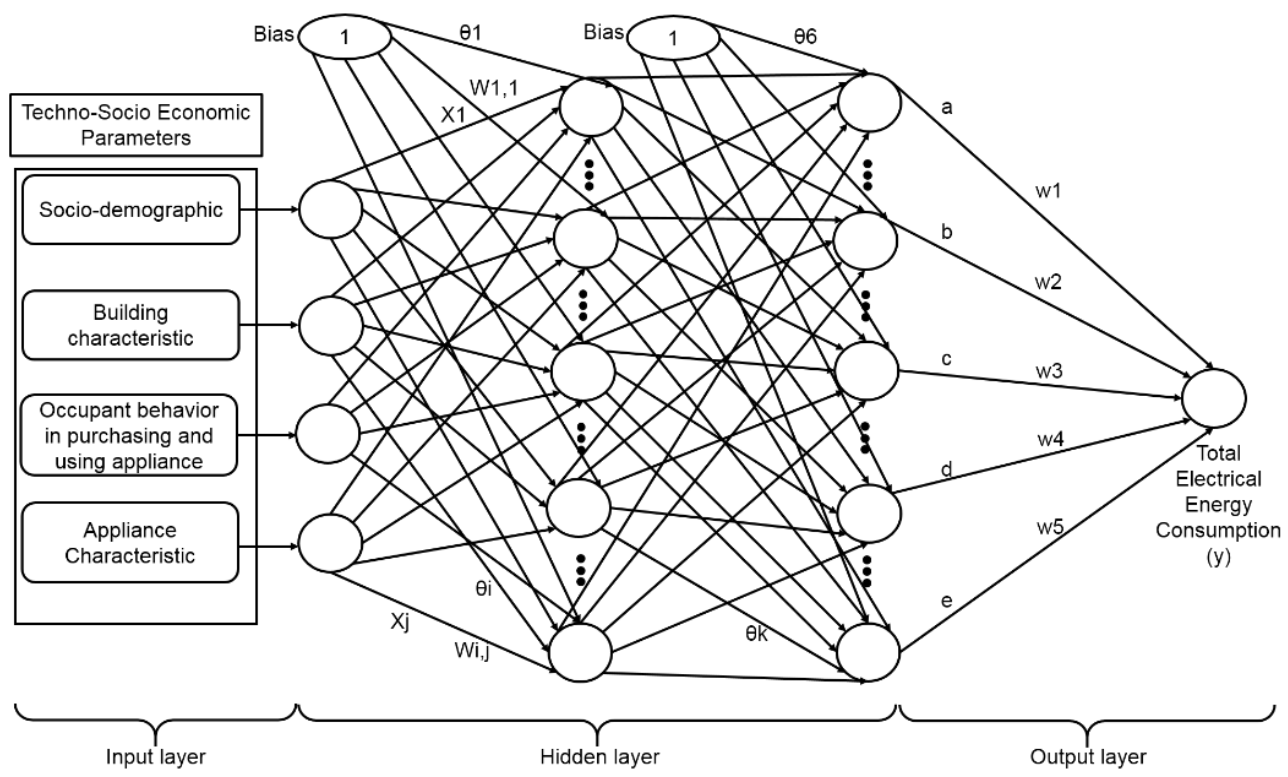

Figure 5. ANN model for estimating short term of total electrical energy consumption based on techno-socio economic approach

\section{CONCLUSION}

Developing of modelling for end-use energy consumption in the residential sector is necessary to ensure the balance system between energy supply and demand under the changes of techno-socio economic factors. Almost none study for estimating the real time of the total electricity energy consumption based on the techno-socio economic approach. The conceptual framework of the estimation model of electrical energy consumption is proposed in this paper in order to contribute to the development of modelling for residential end-use energy consumption in developing countries especially those in the Association of Southeast Asian Nations region, particularly, Malaysia. Artificial Neural Network is selected as the estimation model due to its ability to integrate the quantitative real time and qualitative database and its ability to evaluate the nonlinear relationship amongst techno-socio economic factors. The input of ANN model is techno-socio economic factors from qualitative assessment and the output of ANN model is a short term of the total electrical energy consumption from the quantitative measurement. Electrical energy consumption modelling based on techno-socio economic approach can be utilized to develop some recommendations for energy efficiency strategy. However, the scope of our studies focus on modelling of electrical energy consumption and analyzing the characteristic of short-term of electrical energy consumption based on different technosocio economic factors. Energy efficiency strategy is recommended for further research in this field of study.

\section{ACKNOWLEDGEMENTS}

This study is financially supported by the Malaysian Ministry of Education (MOE) under the Research University Grant (Vot 11H67) and Matching Grant (Vot 00M89) projects of Universiti Teknologi Malaysia.

\section{REFERENCES}

[1] Olivier, J.G., Janssens-Maenhout, G., Muntean, M. and Peters, J.A., Trends in Global CO2 Emissions: 2015 Report: Background Study.JRC report 98184 / PBL report 1803.

[2] Akpan UF, Akpan GE, "The contribution of energy consumption to climate change: A feasible policy direction", International Journal of Energy Economics and Policy, 2012 Jan 1, vol. 2, no. 1, pp. 21.

[3] UNEP, "Buildings and climate change: Summary for decision-makers. United Nations Environmental Programme", Sustainable Buildings and Climate Initiative, Paris. 2009 Dec, pp. 1-62.

[4] Yau YH, Hasbi S, "A review of climate change impacts on commercial buildings and their technical services in the tropics" Renewable and Sustainable Energy Reviews, 2013 Feb, vol. 28, no. 18, pp. 430-41.

[5] Kankal, M., Akpınar, A., Kömürcü, M. İ., Özşahin, T. Ş, "Modelling and forecasting of Turkey's energy consumption using socio-economic and demographic variables", Applied Energy, 2011 Dec, vol. 88. no. 5, pp. 1927-1939. 
[6] Diao, L., Sun, Y., Chen, Z., Chen, J, "Modelling energy consumption in residential buildings: A bottom-up analysis based on occupant behavior pattern clustering and stochastic simulation", Energy and Buildings, 2017 May, vol. 147, pp. 47-66.

[7] Kavgic M, Mavrogianni A, Mumovic D, Summerfield A, Stevanovic Z, Djurovic-Petrovic M, "A review of bottom-up building stock models for energy consumption in the residential sector", Building and environment, 2010 Jul 31, vol. 45, no. 7, pp.1683-1697.

[8] Swan LG, Ugursal VI, "Modeling of end-use energy consumption in the residential sector: A review of modeling techniques", Renewable and sustainable energy reviews, 2009 Oct 31, vol. 13, no. 8, pp. 1819-1835.

[9] Zhou S, Teng F, "Estimation of urban residential electricity demand in China using household survey data", Energy Policy, 2013 Oct 31, vol. 61, pp. 394-402.

[10] Wiesmann D, Azevedo IL, Ferrão P, Fernández JE, "Residential electricity consumption in Portugal: Findings from top-down and bottom-up models", Energy Policy. 2011 May 31, vol. 39, no. 5, pp. 2772-2779.

[11] Szekeres A, Jeswiet J, "Impact of Technological Advancement on Adoption and Use of Residential Heat Pumps", Procedia CIRP, 2016 Dec 31, vol. 48, pp. 394-400.

[12] Buratti C, Orestano FC, Palladino D, "Comparison of the Energy Performance of Existing Buildings by Means of Dynamic Simulations and Artificial Neural Networks", Energy Procedia, 2016 Nov 30, vol. 101, pp. 176-183.

[13] Huebner G, Shipworth D, Hamilton I, Chalabi Z, Oreszczyn T, "Understanding electricity consumption: A comparative contribution of building factors, socio-demographics, appliances, behaviours and attitudes", Applied Energy, 2016 Sep 1, vol. 177, pp. 692-702.

[14] Matsumoto S, "How do household characteristics affect appliance usage? Application of conditional demand analysis to Japanese household data", Energy Policy, 2016 Jul 31, vol. 94, pp. 214-223.

[15] Stoecklein A, Pollard A, Camilery M, Tries J, Isaacs N, "The Household Energy End-Use Project: Measurement Approach and Sample Application of the New Zealand Household Energy Model", In Conference Paper 2001 Apr, no. 87 .

[16] Aydinalp M, A new approach for modelling of residential energy consumption, PhD Thesis, Dalhousie University, Canada, 2002.

[17] Roque M, "Survey and Articifical Neural Network Analysis on Occupant's Household Energy Use in a High-Rise Multi-Unit Residential Building in Toronto, Canada", Master Thesis, Ryerson University, Canada, 2013.

[18] Szüts A, Krómer I, "Estimating Hungarian Household Energy Consumption Using Artificial Neural Networks", ActaPolytechnicaHungarica, 2014 Jan 1, vol. 11, no. 4, pp. 155-168.

[19] Wijaya ME, "Electricity Saving Policy for Household in a Multicultural Society-Indonesia", PhD Thesis, Kyoto University, Japan, 2013.

[20] Azlina AA, Kamaludin M, Abdullah ES, Radam A, "Factors Influencing Household End-Use Electricity Demand in Malaysia", Advanced Science Letters, 2016 Dec 1, vol. 22, no. 12, pp. 4120-3.

[21] Zaki SA, Hagishima A, Fukami R, Fadhilah N, "Development of a model for generating air-conditioner operation schedules in Malaysia", Building and Environment, 2017 Jun 10.

[22] Ranjbar N, Zaki SA, Yusoff NM, Yakub F, Hagishima A, "Short-Term Measurements of Household Electricity Demand During Hot Weather in Kuala Lumpur”, International Journal of Electrical and Computer Engineering (IJECE), 2017 Jun 1, vol. 7, no. 3.

[23] Ranjbar N, Zaki SA, Yusoff NM, Hagishima A, "Time series data analysis of household electricity usage during elnino in Malaysia", In Chemical Engineering Transactions 2017, Italian Association of Chemical EngineeringAIDIC.

[24] Kumar R, Aggarwal RK, Sharma JD, "Energy analysis of a building using artificial neural network: A review" Energy and Buildings, 2013 Oct 31, vol. 65, pp. 352-358.

[25] Biswas MR, Robinson MD, Fumo N, "Prediction of residential building energy consumption: A neural network approach", Energy, 2016 Dec 15, vol. 117, pp. 84-92.

[26] Siang J.J., "Jaringan Syaraf Tiruan \& Pemrogramannya Menggunakan Matlab", $1^{\text {st }}$ Edition, Yogyakarta, Penerbit Andi, 2005, 307.

[27] Jones RV, Fuertes A, Lomas KJ, "The socio-economic, dwelling and appliance related factors affecting electricity consumption in domestic buildings", Renewable and Sustainable Energy Reviews, 2015 Mar 31, vol. 43, pp. 901-917.

[28] Mizobuchi K, Takeuchi K, "Replacement or additional purchase: The impact of energy-efficient appliances on household electricity saving under public pressures”, Energy Policy, 2016 Jun 30, vol. 93, pp. 137-148.

[29] Huebner GM, Hamilton I, Chalabi Z, Shipworth D, Oreszczyn T, "Explaining domestic energy consumption-the comparative contribution of building factors, socio-demographics, behaviours and attitudes", Applied energy, 2015 Dec 1, vol. 159, pp. 589-600.

[30] Batih H, Sorapipatana C, "Characteristics of urban households' electrical energy consumption in Indonesia and its saving potentials", Renewable and Sustainable Energy Reviews, 2016 May 31, vol. 57, pp. 1160-1173.

[31] Wahlström MH, Hårsman B, "Residential energy consumption and conservation", Energy and Buildings, 2015 Sep 1, vol. 102, pp. 58-66.

[32] McLoughlin F, Duffy A, Conlon M, "Characterising domestic electricity consumption patterns by dwelling and occupant socio-economic variables: An Irish case study", Energy and Buildings, 2012 May 31, vol. 48, pp. 240-248.

[33] Brounen D, Kok N, Quigley JM, "Residential energy use and conservation: Economics and demographics. European Economic Review, 2012 Jul 31, vol. 56, no. 5, pp. 931-945. 
[34] Wyatt P, "A dwelling-level investigation into the physical and socio-economic drivers of domestic energy consumption in England", Energy Policy, 2013 Sep 30, vol. 60, pp. 540-549.

[35] Leahy E, Lyons S, "Energy use and appliance ownership in Ireland", Energy Policy, 2010 Aug 31, vol. 38, no. 8, pp. 4265-4279.

[36] Bedir M, Hasselaar E, Itard L, "Determinants of electricity consumption in Dutch dwellings", Energy and buildings, 2013 Mar 31, vol. 58, pp. 194-207.

[37] Sanquist TF, Orr H, Shui B, Bittner AC, "Lifestyle factors in US residential electricity consumption", Energy Policy, 2012 Mar 31, vol. 42, pp. 354-364.

\section{BIOGRAPHIES OF AUTHORS}
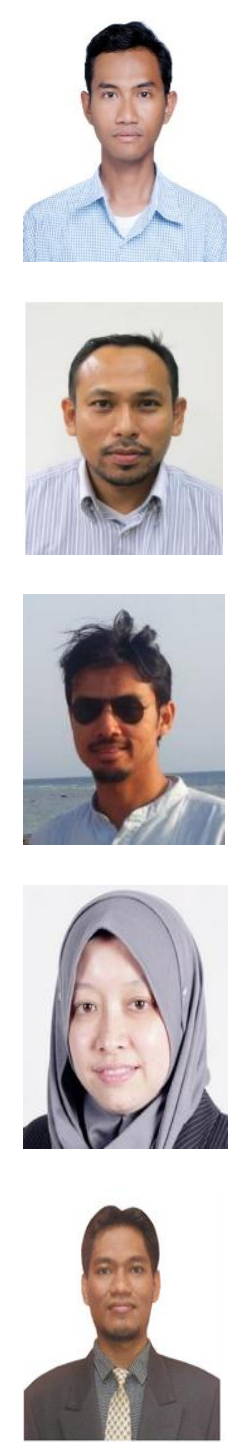

Boni Sena received his B.Eng in Physics Engineering in 2009 and M.Eng in Mechanical Engineering from Gadjah Mada University in 2012. He is currently a $\mathrm{PhD}$ student under the supervision of Dr. Sheikh Ahmad Zaki in Malaysia Japan International Institute of Technology, Universiti Teknologi Malaysia. His research is about modelling of electrical energy consumption based on techno-socio economic approach.

Sheikh Ahmad Zaki Shaikh Salim obtained his Dip.Eng, B.Eng, and M.Eng from Universiti Teknologi Malaysia. He received Ph.D in Energy and Environmental Engineering from Kyushu University in 2011. Currently, he is a senior lecturer at Department of Mechanical Precision Engineering, Malaysia-Japan International Institute of Technology (MJIIT), Universiti Teknologi Malaysia. His research mainly focuses on urban climatology, building and environmental engineering, and wind engineering.

Fitri Yakub received his Dip.Eng, and B.Eng, in Mechatronics Engineering and Electronics Engineering from Universiti Teknologi Malaysia in 2001 and 2006 respectively. He obtained MSc. in Mechatronics Engineering from International Islamic University Malaysia in 2011. He received doctorate in Automatic Control Laboratory, Tokyo Metropolitan University in 2015. He is now with the Malaysia-Japan International Institute of Technology since 2012. His field of research interest includes intelligent control, automatic and robust control, and motion control systems.

Nelidya Md Yusoff received her B.Eng in Electrical-Telecommunication from Universiti Teknologi Malaysia in 2002. In 2004, she obtained her MSc in Digital Communication Systems from Loughborough University, United Kingdom. She received her PhD in Photonics and Fiber Optics System Engineering from Universiti Putra Malaysia in 2013. She is now a senior lecturer at UTM Razak School of Engineering and Advanced Technology. Her research interest includes discrete and remote Erbium doped Fiber amplifier, optical amplifiers, and optical communication systems.

Mohammad Kholid Ridwan obtained his B.Eng in Electrical Engineering from Gadjah Mada University. In 2001, he received M.Sc in Sustainable Energy Engineering from Royal Institute of Technology (KTH), Stockholm, Sweden. He obtained Dr. Eng in Urban and Energy Environment from Tokyo Insitute of Technology, Japan on 2007. His research interests are energy modelling, forecasting energy supply/demand based on time series or cross sectional data and Energy Management System (EMS). 